\title{
HALLUKS VALGUS TEDAVISINDE MODIFIYE CHEVRON OSTEOTOMISI UYGULAMALARIMIZIN ORTA VE UZUN DÖNEM SONUÇLARI
}

\author{
MID AND LONG TERM RESULTS OF MODIFIED CHEVRON OSTEOTOMY \\ IN HALLUX VALGUS
}

\author{
Barış YILMAZ1 ${ }^{1}$ Cem ÇOPUROĞLU², Mert ÖZCAN², Mert ÇiFTDEMIR², \\ Kağan Volkan ÜNVER ${ }^{3}$, Nurettin HEYBELi \\ ${ }^{1}$ Fatih Sultan Mehmet Eğitim ve Araştırma Hastanesi, Ortopedi ve Travmatoloji Kliniği \\ 2 Trakya Üniversitesi Tıp Fakültesi Hastanesi, Ortopedi ve Travmatoloji Anabilim Dalı \\ 3 İnegöl Devlet Hastanesi, Ortopedi ve Travmatoloji Kliniği
}

\section{Cite this article as: Yılmaz B, Çopuroğlu C, Özcan M, Çiftdemir M, Ünver KV, Heybeli N. Mid and long term results of modified chevron osteotomy in hallux valgus. Med J SDU 2019; 26(3): 306-311.}

\section{Öz}

\section{Amaç}

Halluks valgus nedeniyle modifiye Chevron osteotomisi uyguladığımız olgularımızın orta ve uzun dönem sonuçlarını değerlendirdik.

\section{Gereç ve Yöntem}

Takip süreleri 24 aydan uzun-60 aydan kısa olan 37 olgu (\%57.8) orta dönem takip olguları (Grup 1) ve takip süresi 60 aydan uzun olanlar 27 olgu (\%42.2) (Grup 2) uzun dönem takip olguları olarak belirlendi. Tüm olguların yaş, cinsiyet, taraf ve takip süreleri kaydedildi. Cerrahi öncesi ve son kontrollerinde halluks valgus açısı ve intermetatarsal açıları ölçüldü. Klinik sonuçlar Amerikan Ortopedik Ayak-Ayak Bileği Derneği Skorları (AOFAS) ile değerlendirildi.

\section{Bulgular}

Çalışma 21'i (\%32.8) erkek, 43'ü (\%67.2) erkek toplam 64 olgu ile yapılııştır. Yaş ortalaması $47.41 \pm 9.80$ (21-74) yıldır. Ortalama takip süreleri $53.25 \pm 19.18$ (24-93) aydır. Olguların 34'ünün (\%53.1) sağ, 30'unun (\%46.9) sol tarafına cerrahi uygulanmıştır. HVA orta-

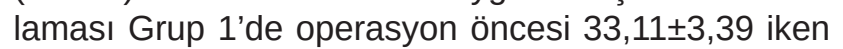
operasyon sonrası $14,59 \pm 1,88$; Grup 2'de ise operasyon öncesi $33,85 \pm 3,58$ iken operasyon sonrası 14,11 $\pm 1,91$ bulunmuştur. IMA ortalaması Grup 1'de operasyon öncesi $11,43 \pm 1,3$ iken operasyon sonrası $7,76 \pm 1,5$; Grup 2'de ise operasyon öncesi $11,7 \pm 1,3$ iken operasyon sonrası 7,74 $\pm 1,56$ bulunmuştur. Grupların AOFAS değerlendirmeleri için Grup 1 de operasyon öncesi ortalama 50,03 $\pm 8,09$ iken operasyon sonrası 90,35 $\pm 6,75$ bulundu. Buna karşılık Grup 2 de operasyon öncesi $49,78 \pm 8,96$ iken operasyon sonrası $90,26 \pm 6,59$ olarak bulundu.

\section{Sonuç}

Modifiye Chevron osteotomisi uygulanan olguların klinik sonuçlarının hasta memnuniyeti açısından, hem orta hem de uzun dönemde iyi olduğu, hallux valgus deformitesinin cerrahi tedavisinde uygun olgularda tercih edilebilecek iyi bir cerrahi metod olarak görülmektedir.

Anahtar Kelimeler: Hallux valgus, Modifiye Chevron osteotomisi, AOFAS

\section{Abstract}

\section{Introduction}

We evaluated mid and long term results of modified Chevron osteotomy in hallux valgus patients.

Materials and Method: Patients are assigned two groups; Group 1 who have a follow-up period between

İletişim kurulacak yazar/Corresponding author: drbyilmaz@yahoo.com

Müracaat tarihi/Application Date: 30.09.2018 • Kabul tarihi/Accepted Date: 26.10.2018

Available online at http://dergipark.gov.tr/sdutfd

Makaleye http://dergipark.gov.tr/sdutfd web sayfasından ulaşılabilir. 
24-60 months (37 patients:\%57,8) and Group 2 longer than 60 months (27 patients:\%42,2). All patients' age, sex, operation side and follow-up periods were recorded. Hallux valgus angle (HVA) and intermetatarsal angle (IMA) were evaluated pre and postoperatively. Clinical results were evaluated with American Orthopaedic Foot and Ankle Society (AOFAS) scoring system.

\section{Results}

We evaluated 64 patients and there were 21 male $(\% 32,8)$ and 43 female $(\% 67,2)$ patients. Mean age was $47,41 \pm 9.80$ (21-74). Mean follow-up period was $53.25 \pm 19.18$ (24-93) months. 34 patients $(\% 53,1)$ were operated from right side while 30 patients $(\% 46,9)$ from left. Mean HVA angle was $33,11 \pm 3,39$ changed to $14,59 \pm 1,8$ in Group 1, while these changes were $33,85 \pm 3,58$ to $14,11 \pm 1,91$ in Group 2. Mean IMA was $11,43 \pm 1,3$ changed to $7,76 \pm 1,5$ in Group 1, while these changes were $11,7 \pm 1,3$ to $7,74 \pm 1,56$ in Group 2. Mean AOFAS score was $50,03 \pm 8,09$ changed to $90,35 \pm 6,75$ in Group 1, while mean AOFAS score was $49,78 \pm 8,96$ changed to $90,26 \pm 6,59$ in Group 2 .

\section{Conclusion}

Modified Chevron osteotomy appears to be a good surgical method for patients with hallux valgus deformity, which is better in both middle and long term, in terms of patient satisfaction.

Keywords: Hallux valgus, Modified Chevron osteotomy, AOFAS.

\section{Giriş}

Halluks Valgus (HV), birinci parmağın abduksiyon kontraktürü ve laterale deviasyonu olarak tanımlanmış olup, ilerleyen durumlarda günlük aktivitelerini ileri derecede kısıtlayan, ayağın estetik görünümünü bozan, ayak başparmağının ağrılı ve ilerleyici bir hastalıktır $(1,2)$. Başlangıçta ayakkabı modifikasyonu, kilo verdirilme ve parmak arası ortez kullanımı gibi konservatif yöntemler ile tedavi edilmeye çalışılmaktadır. Ancak deformitenin ileri evrelerinde çoğu zaman cerrahi tedavi yöntemleri gerekmektedir(3,4).

Cerrahi tedavide amaç, ağrıyı ortadan kaldırmak ve estetik olarak bir düzelme elde etmektir. Literatürde deformitenin şiddetine göre; metatarso-falangeal yumuşak doku rekonstrüksiyonu, 1.metatarsın distalden yada proksimalden yapılan osteotomisi, proksimal falangeal osteotomi, medial küneiform osteotomisi, metatarso-falangeal eklem artrodezi, rezeksiyon artroplastisi yada bunların birlikte uygulanması gibi birçok cerrahi prosedür bildirilmiştir. Bununla birlikte tüm bu prosedürler içinde distal metatarsal osteotomiler, bunlar arasında da modifiye chevron osteotomisini komplikason ve nüks oranı düşük olması ile ön plana çıkmıştır(5,6).

Çalışmamızda; halluks valgus deformitenin tedavi yöntemleri arasından deformitenin uygunluğuda göz önüne alınarak distal metatarsal osteotomi metodu olarak seçtiğimiz modifiye chevron osteotomisi uyguladığımız olgularımızın orta ve uzun dönem sonuçlarını karşılaştırarak bu prosedürün sadece orta dönemde değil, aynı zamanda uzun dönemde de etkinliğinin devam ettiğini göstermeyi amaçladık.

\section{Gereç ve Yöntem}

Kiniğimizde hallux valgus tanısı konulduktan sonra cerrahi onamları alınarak modifiye chevron osteotomisi uygulanan olgular retrospektif olarak değerlendirildi. Tüm olgular aynı cerrahi ekip tarafından opere edilmişlerdi. Tüm olgular için osteotomi sonrası fiksasyon 1 adet başsız kanüle vida uygulanarak sağlanmıştı. Sonrasında hastalara 3 hafta kısa bacak atel uygulanmış ve yere basmamaları istenmişti. Olguların 3.hafta da dikişleri alınarak atel uygulamaları sonlandırılmış, sadece topuklarına basmalarına, 6 . haftadaki radyolojik kontrollerinde kaynama görüldükten sonra tam yük vererek basmalarına izin verilmişti.

Bununla birlikte başka bir hallux valgus cerrahi prosedürü uygulanan olgular çalışma kapsamına alınmadılar. Aynı zamanda nükse neden olabilecek ya da hasta memnuniyetini etkileyebilecek romatoid artrit, hipotiroidizm, gut gibi sistemik hastalıklar, diabetik nöropati,herediter nöromüsküler hastalıklar gibi nörolojik bozukluklar, Parkinsonizm, serebral felç,genel eklem laksitesi, eklem kontraktürü ve metatarsofalangeal eklem artriti nüks eğilimi yaratan hasta kaynaklı patolojilerin varlığı olguların çalışma kapsamına alınmama kriteri olarak kabul edildi.

Öncelikle tüm olguların yaş, cinsiyet, taraf ve takip süreleri kayıt edildi. Sonrasında olguların cerrahi öncesi (Resim 1,2) ve son kontrollerindeki (Resim 3,4) yere basarken çekilen ön-arka radyografilerden halluks valgus açıSı (HVA) ve intermetatarsal açı (IMA) ölçülerek karşılaştıııldı. Operasyonların klinik sonuçlarının karşılaştırılması ise operasyon öncesi ve son takiplerindeki Amerikan Ortopedik Ayak-Ayak Bileği Derneği Skorları (AOFAS) ile yapıldı (Resim 5). 


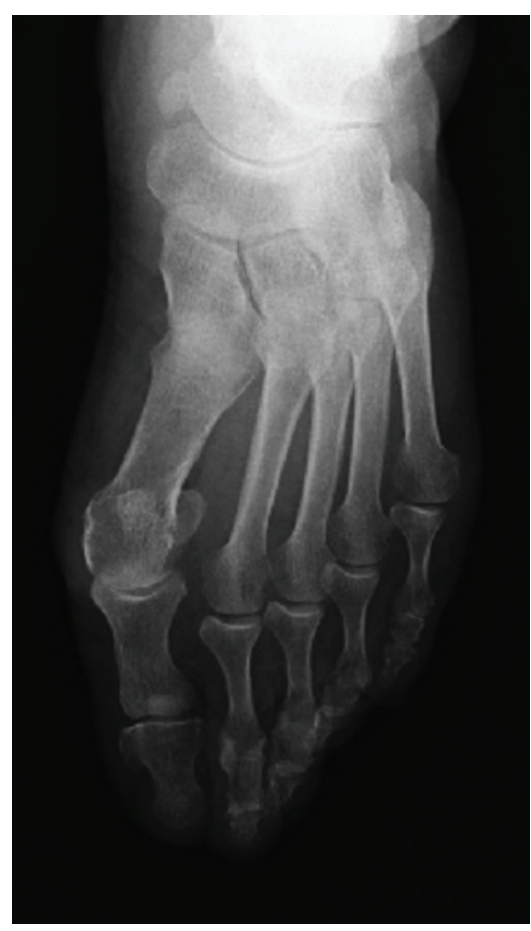

Resim 1: Hallux Valguslu bir olgunun modifiye Chevron osteotomi operasyonu öncesi ön-arka radyolojik görüntüsü

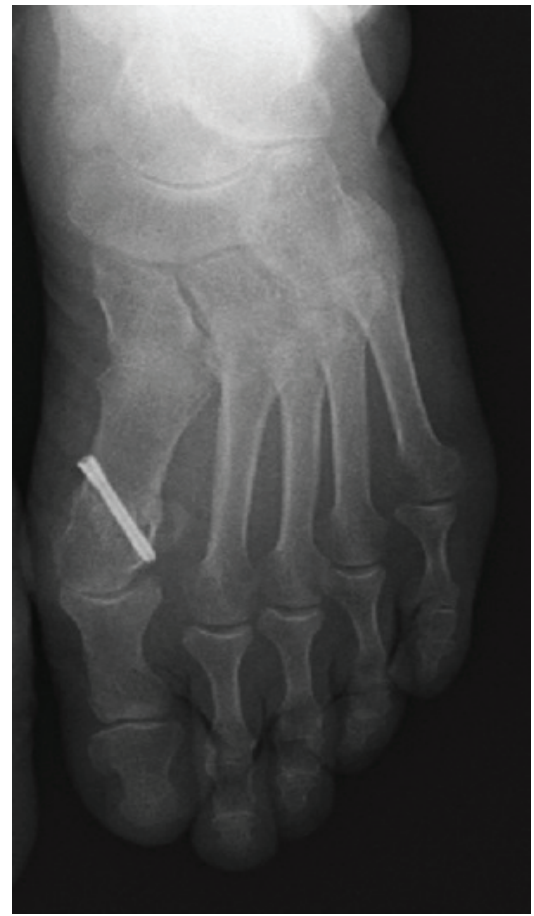

Resim 3: Hallux Valguslu bir olgunun modifiye Chevron osteotomi operasyonu sonrası ön-arka radyolojik görüntüsü

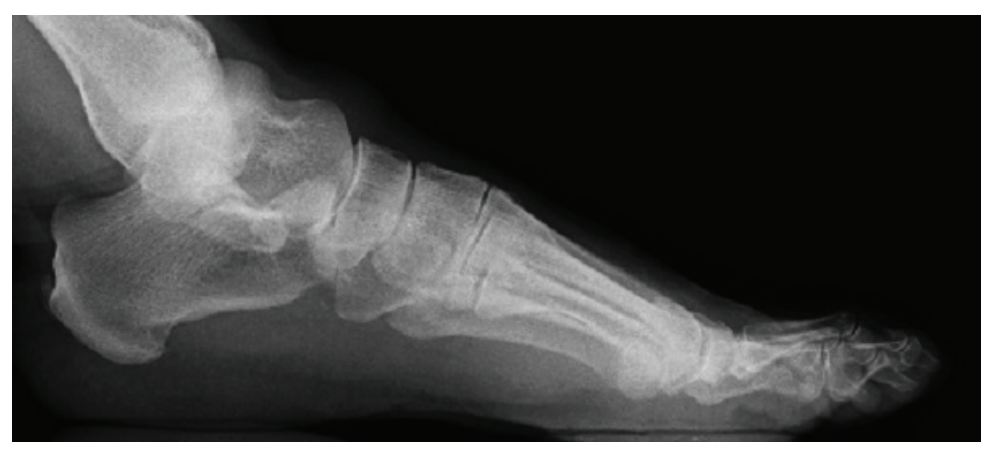

Resim 2: Hallux Valguslu bir olgunun modifiye Chevron osteotomi operasyonu öncesi yan radyolojik görüntüsü

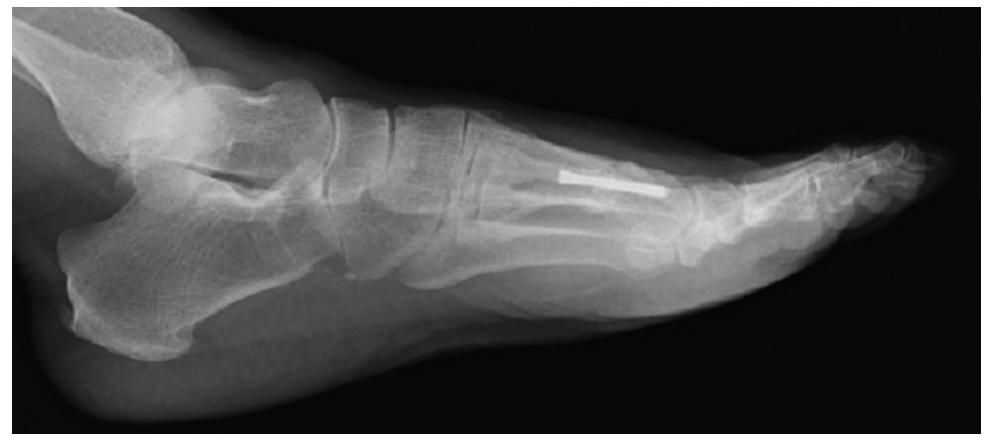

Resim 4: Hallux Valguslu bir olgunun modifiye Chevron osteotomi operasyonu sonrası yan radyolojik görüntüsü

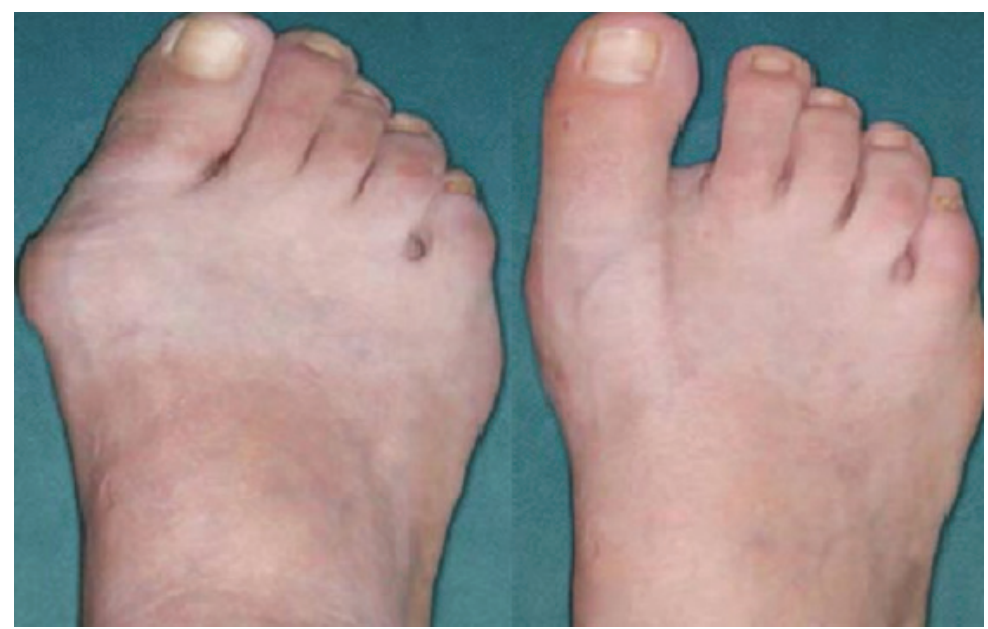

Resim 5: Operasyon öncesi ve sonrası ayağın klinik görüntüsü 
Çalıșmada elde edilen bulgular değerlendirilirken, istatistiksel analizler için IBM SPSS (v.22, Türkiye) programı kullanıldı. Çalışma verileri değerlendirilirken parametrelerin normal dağılıma uygunluğu Shapiro Wilks Testi ile değerlendirilmiştir. Çalışma verileri değerlendirilirken tanımlayıcı istatistiksel metodların (Ortalama, Standart sapma, Frekans) yanı sıra niceliksel verilerin karşılaştırılmasında normal dağılım gösteren parametrelerin iki grup arası karşılaştırmalarında Student t test, normal dağılım göstermeyen parametrelerin iki grup arası karşılaştırmalarında Mann Whitney $\mathrm{U}$ test kullanıldı. Anlamlılık $\mathrm{p}<0.05$ düzeyinde değerlendirildi.

\section{Bulgular}

Çalışma 21'i (\%32.8) erkek, 43'ü (\%67.2) kadın olmak üzere toplam 64 olgu ile yapılmıştır. Olguların yaş ortalaması $47.41 \pm 9.80$ (21-74) yıldır. Olguların ortalama takip süreleri ise $53.25 \pm 19.18$ (24-93) aydır. Olguların 34'ünün (\%53.1) sağ, 30'unun (\%46.9) sol tarafına cerrahi uygulanmıştır.

HV tanısı nedeniyle modifiye Chevron osteotomisi uygulanan olguların takip süreleri 24 aydan uzun-60 aydan kısa olanlar 37 (\%57.8) olgu (Grup 1) ve takip süresi 60 aydan uzun olanlar 27 (\%42.2) olgu (Grup 2) idi. Grup 1 için takip süresi 40.32 ay iken, Grup 2 için takip süresi ortalama 73.02 ay idi.

Grup 1 de operasyon öncesi HVA ortalaması $33,11 \pm 3,39$ iken operasyon sonrası $14,59 \pm 1,88$; Grup 2 de ise operasyon öncesi HVA ortalaması $33,85 \pm 3,58$ iken operasyon sonrası $14,11 \pm 1,91$ olarak bulunmuştur. Yine Grup 1 de operasyon öncesi IMA ortalaması $11,43 \pm 1,3$ iken operasyon sonrası $7,76 \pm 1,5$; Grup 2 de ise operasyon öncesi IMA orta- laması $11,7 \pm 1,3$ iken operasyon sonrası $7,74 \pm 1,56$ olarak bulunmuştur. Bu sonuçlara göre operasyon öncesi ve sonrası HVA ve IMA değerlendirmelerine göre gruplar arasında istatistiksel olarak anlamlı bir farklılık bulunmamaktadır ( $p>0.05)$.

Grupların klinik değerlendirmelerinin yapıldığı AOFAS için Grup 1 de operasyon öncesi ortalama 50,03 $\pm 8,09$ iken operasyon sonrası $90,35 \pm 6,75$ bulundu. Buna karşılık Grup 2 de operasyon öncesi 49,78 $\pm 8,96$ iken operasyon sonrası 90,26 $\pm 6,59$ olarak bulundu. Bu sonuçlara göre gruplar arasında istatistiksel olarak anlamlı bir farklıık bulunmamaktadır ( $p>0.05$ ) (Tablo 1).

\section{Tartışma}

Hallux valgus tanısı ile modifiye chevron osteotomisi uyguladığımız vakalarımızda orta ve uzun dönem sonuçlarını karşılaştırdığımızda sonuçlar arasında anlamlı fark görülmemesi, bu tedavinin başarılı klinik sonuçlarının sadece orta dönemde değil, aynı zamanda uzun dönemde de etkinliğinin devam ettiğini göstermektedir (7).

Halluks valgus deformitesi için tedavi yöntemine karar verirken öncelikle hastanın asıl şikayeti, mesleği, yaşam şekli ve aktiviteleri göz önünde bulundurulmalıdır. Bu şekilde hastanın beklentilerine en uygun tedavi belirlenebilecektir(8-10). Bu nedenle öncelikle konservatif yöntemler denenmelidir. Ancak deformitenin çok ciddi ve ağrılı olduğu durumlarda konservatif tedavinin faydalı olmayacağı düşünülüyorsa doğrudan cerrahi tedavi önerilebilir.

Halluks valgus da cerrahi tedaviye karar verirken öncelikle deformitelerin birbirinden farklı komponentler içerebileceği unutulmamalıdır. Bu nedenle uygulana-

(IMA:Intermetetarsal açı, HVA:Halluks Valgus açı, AOFAS:Amerikan Ortopedik Ayak-Ayak Bileği Derneği Skorları)

\begin{tabular}{|c|c|c|c|}
\hline & Orta $(n=37)$ & Uzun ( $n=27)$ & $\mathbf{p}$ \\
\hline & Ort $\pm S S$ & Ort+SS & \\
\hline Pre-op HVA & $33,11 \pm 3,39$ & $33,85 \pm 3,58$ & ${ }^{1} 0,400$ \\
\hline Post-op HVA (medyan) & $14,59 \pm 1,88(15)$ & $14,11 \pm 1,91(14)$ & ${ }^{2} 0,307$ \\
\hline Pre op IMA (medyan) & $11,43 \pm 1,3(11)$ & $11,7 \pm 1,3(11)$ & ${ }^{2} 0,369$ \\
\hline Post op IMA (medyan) & $7,76 \pm 1,5(8)$ & $7,74 \pm 1,56(8)$ & ${ }^{2} 0,917$ \\
\hline Pre-op AOFAS & $50,03 \pm 8,09$ & $49,78 \pm 8,96$ & ${ }^{1} 0,908$ \\
\hline Post-op AOFAS & $90,35 \pm 6,75$ & $90,26 \pm 6,59$ & ${ }^{1} 0,957$ \\
\hline
\end{tabular}

${ }^{1}$ Student t Test $\quad{ }^{2}$ Mann Whitney U Test $\quad$ " $\mathrm{p}<0.05$ 
cak cerrahi girişimin hedefi ayağın normal fonksiyonunu geri kazandırmak için normal anatominin sağlanması olmalıdır. Bu amaçla deformitenin operasyon öncesi tipi, yeri ve şiddeti açıkça ortaya konmalı ve olguya en uygun olan operasyon planlanmalıdır. Günümüzde halluks valgus deformitesi için genel olarak metatarsofalangeal yumuşak doku prosedürleri, distal yada proksimal metatarsal osteotomiler, proksimal falangeal veya medial küneiform osteotomiler, metatarsofalangeal eklem artrodezi, rezeksiyon artroplastisi ya da bunların birlikte uygulanması gibi cerrahi prosedürler yapılabilmektedir. Bununla birlikte genel olarak çoğunlukla yapılan değelendirmelerde çoğu hasta için metatarsal osteotomiler yeterli cerrahi yöntem olarak görülebilmekte, bunlar da proksimal, diafizeal ve distal olarak üçe ayrılmaktadırlar (11). Literatürde bu osteotomilerin belli başlıları arasında Reverdin, Hohmann, Mitchell, Wilson ve Chevron osteotomileri sayılabilir.

Çalışmamıza konu olan Chevron osteotomi tekniği bir distal metatarsal osteotomidir. Bu osteotominin uygulanma kritlerleri olarak literatürde; HVA için 20 derecenin, IMA açı için 40 derecenin altında olması gerektiği rapor edilmiştir. Chevron osteotomisi özellikle orta derecede halluks valgusu olan metatarsus primus varuslu hastalarda mükemmel sonuçlar verdiğini bir çok çalışmada bildirmiştir(12-15). Gerçekten de Chevron osteotomisi ile ön ayak önemli ölçüde daralmakta ve bunyon ile ilgili şikayetler ortadan kalkmaktadır. Bu osteotominin en iyi yönlerinden birisi de 1.metatars uzunluğunda bir değişiklik olmamasıdır. Yine diğer avantajları da stabil olması, dorsal angulasyon ve deplasmana neden olmamasıdır(16). Stabil bir osteotomi olması nedeniyle hastaların kısa süreli bir alçı tesbitinden sonra erken yürütülebileceği açıklanmıştır. Biz de çalışmamızda olgularımıza osteotomi hattında radyografik olarak kaynama görülene kadar yürüme alçısı uyguladık ki, bu süre ortalama 6 haftaydı. Ancak son yapılan çalışmalarda bu osteotomisinin son derece stabil olması nedeni ile yürüme alçısı uygulamasının bu kadar uzun süre gerekmediği de bildirilmeye başlanmıştır. Bizde son zamanlarda olgularımıza bu osteotomiyi takiben 3 hafta yürüme alçısı, 6. haftaya kadar kısmi yük sonrasında normal yürümeye başlanabileceğini düşünmeye başladık.

Hem Mitchell hem de AOFAS değerlendirmeleri ağrı, fonksiyon ve kozmetik üzerine yapılan değerlendirmelerdir. Bununla birlikte doğrudan bu değerlendirmeler içinde olmayan ancak sonuçları bakımından bu değerlendirmelerin sonuçlarını etkilediğini düşündüğümüz bazı cerrahi ayrıntılar da vardır. Örneğin yapılan kapsülorafinin çok gergin olması MP eklernde hareket kısıtııı̆ıına yol açacağından kapsülorafiyi normal bir gerginlikte yapmak, yine cerrahi sırasında dorso me- dial kutanöz sinirin mediale ekarte ederek korunması, istenmeyen komplikasyonların ortaya çıkmaması yönünden önemlidir $(17,18)$. Operasyon sonrası olgularda ayakkabı giymekte duyulan sıkıntı istenmeyen bir sonuçtur. Biz değerlendirme sonuçlarını olumsuz etkileyen bu sorunlarla ne orta dönem ne de uzun dönem takiplerinde hiç karşılaşmadık. Bunu medial çıkıntının eksizyonu ve distal parçanın lateralizasyonundan sonra oluşan ve genellikle nasırlı cilt fazlalığını dikkatli ve uygun bir şekilde eksize ederek cildi kapatmamıza bağlıyoruz.

Litaratür araştırması yaptığımızda Chevron osteotomisinin sonuçlarının farklı fiksasyon yapılsa da genel olarak iyi olduğu görülmektedir $(19,20)$. Bunun en önemli nedeni de osteotomi sonrası son derece fiksasyon yapılabilmesine bağlanmaktadır. Lewis ve arkadaşlarının stabiliteyi artırmak için 60 derecenin altında uyguladıkları osteotominin sonuçları(21), Home ve arkadaşlarının 76 hastada chevron osteotomisi sonuçları (22), Lillich ve Baxter 1986 yılında 2 orta ve uzun mesafe koşucusunda uyguladıkları chevron osteotomisi sonuçları (23) hep olumlu olmuştur. Benzer şekilde Grill ve arkadaşları başarı oranlarını \% 84.2 olarak açıklamışlardır(24).

Chevron osteotomisi sonuçları her ne kadar oldukça iyi olarak bilinse de, diğer osteotomiler ile de karşıIaştırılmıştır. Örneğin Klosog ve arkadaşları chevron osteotomisini Wilson tekniği ile karşılaştırmışlar ve subjeklif değerlendirmelerinde chevron tekniği sonuçIarını daha iyi bulmuşlardır(25). Bununla birlikte Kinnard ve Gordon 1984'de Meier ve Kenzora 1985'de, Chevron ve Mitchell tekniklerini karşılaştırmışlar ve aralarında çok büyük bir farklılık olmadığını belirtmişlerdir $(26,27)$.

Literatür araştırmamız Chevron osteotomisi ile ilgili çalışma sonuçlarında farklı görüşlerin de olduğunu ortaya koymuştur. Ancak bu farklı sonuçlar genel olarak tekniğin uygulanmasındaki hatalara ve ortaya çıkan çeşitli komplikasyonlara bağlanmıştır. Bizim çalışmamızın ise, litertürde hiç olmayan Chevron osteotomisi sonuçlarını orta ve uzun dönem olarak karşılaştırması bakımından önemli olduğu kanısındayız. Chevron osteotomisi sonuçlarının orta ve uzun dönem takiplerinde anlamlı fark olamaması son derece önemlidir. Yine uygulanmasının kolay, stabilitenin iyi olması, mükemmel fonksiyonel ve kozmetik sonuçları ve düşük komplikasyon oranı ile tavsiye edilen bir cerrahi teknik olarak unutulan değil uygun endikasyon ile ve doğru cerrahi uygulama ile sonuçları bilinen ve güvenilir bir yöntem olarak tercih edilmesi gerektiğini düşünmekteyiz. 


\section{Çıkar iliş̧kisi Açıklaması: Yazarlar arasında çıkar ilişkisi çatışması yoktur.}

\section{Kaynaklar}

1. Perera AM, Mason L, Stephens MM. The pathogenesis of hallux valgus. J Bone Joint Surg Am. 2011 Sep 7;93(17):16501661.

2. Coughlin MJ, Jones CP. Hallux valgus: demographics, etiology, and radiographic assessment. Foot Ankle Int. 2007 Jul;28(7):759-777.

3. Coughlin MJ. Hallux Valgus. J Bone Joint Surg Am.1996; 78(6): 932-966.

4. Robinson AH, Limbers JP. Modern concepts in the treatment of hallux valgus. J Bone Joint Surg Br. 2005 Aug; 87(8): 10381045.

5. Schneider W, Aigner N, Pinggera O, Knahr K. Chevron osteotomy in hallux valgus. Ten-year results of 112 cases. J Bone Joint Surg Br. 2004 Sep;86(7):1016-20.

6. Austin DW, Leventen EO. A new osteotomy for hallux valgus: a horizontally directed "V" displacement osteotomy of the metatarsal head for hallux valgus and primus varus. Clin Orthop Relat Res. 1981 Jun;(157):25-30.

7. Fuhrmann $\mathrm{R}$, Anders $\mathrm{J}$. The long-term results of resection arthroplasties of the first metatarsophalangeal joint in rheumatoid arthritis. Int Orthop. 2001 Oct; 25(5): 312-316.

8. Toepfer A, Harrasser N, Lenze F, Pohlig F, von Eisenhart-Rothe R. Current concepts in diagnostics and treatment of hallux valgus deformity. MMW Fortschr Med. 2015 Jun 11;157(11):37-40.

9. Hart ES, deAsla RJ, Grottkau BE. Current concepts in the treatment of hallux valgus. Orthop Nurs. 2008 Sep-Oct;27(5):274-80; quiz 281-2.

10. Tai CC, Ridgeway S, Ramachandran M, Ng VA, Devic N, Singh D. Patient expectations for hallux valgus surgery. J Orthop Surg (Hong Kong). 2008 Apr;16(1):91-5.

11. Lindgren U, Turan I: A new operation for hallux valgus. Clin Orthop Relat Res. 1983 May; (175):179-183.

12. Velkes S, Ganel A, Nagris B, Lokiec F. Chevron osteotomy in the treatment of hallux valgus.J Foot Surg. 1991 MayJun;30(3):276-8.

13. Horne G, Tanzer T, Ford M. Chevron osteotomy for the treatment of hallux valgus.Clin Orthop Relat Res. 1984 Mar;(183):32-6.

14. Johnson KA, Cofield RH, Morrey BF. Chevron osteotomy for Hallux Valgus. Clin Orthop Relat Res.1979 Jul-Aug; (142):4447.

15. Zimmer TJ, Johnson KA, Klassen RA. Treatment of hallux valgus in adolescents by the chevron osteotomy. Foot Ankle. 1989 Feb;9(4):190-3.

16. Okuda R, Kinoshita M, Morikawa J, Yasuda T, Abe M. Proximal metatarsal osteotomy: relation between 1- to greater than 3-years results. Clin Orthop Relat Res. 2005 Jun;(435):191-6.

17. Veri JP, Pirani SP, Claridge R. Crescentic proximal metatarsal osteotomy for moderate to severe hallux valgus: a mean 12.2 year follow-up study. Foot Ankle Int. 2001 Oct;22(10):817-22.

18. Sammarco GJ, Idusuyi OB. Complications after surgery of the hallux. Clin Orthop Relat Res. 2001 Oct:(391):59-71.

19. Komur B, Yilmaz B, Kaan E, Yucel B, Duymus TM, Ozdemir G, Guler O. Mid-Term Results of Two Different Fixation Methods for Chevron Osteotomy for Correction of Hallux Valgus. J Foot Ankle Surg. 2018 Sep - Oct;57(5):904-909.

20. Guler O, Yilmaz B, Mutlu S, Cerci MH, Heybeli N. Distal Oblique Metatarsal Osteotomy for Hallux Valgus Deformity: A Clinical Analysis. J Foot Ankle Surg. 2017 May - Jun;56(3):497-504.

21. Lewis RJ, Feffer HL. Modified chevron osteotomy of the first metatarsal. Clin Orthop Relat Res. 1981 Jun;(157):105-9.

22. Horne G, Tanzer T, Ford M. Chevron osteotomy for the treatment of hallux valgus. Clin Orthop Relat Res. 1984 Mar;(183):32-6.

23. Lillich JS, Baxter DE. Bunionectomies and related surgery in the elite female middle-distance and marathon runner. Am J Sports Med. 1986 Nov-Dec;14(6):491-3.

24. Grill F, Hetherington V, Steinböck G, Altenhuber J. Experiences with the chevron (V-) osteotomy on adolescent hallux valgus. Arch Orthop Traum Surg.1986;106(1):47-51.

25. Klosok JK, Pring DJ, Jessop JH, Maffulli N. Chevron or Wilson metatarsal osteotomy for hallux valgus. A prospective randomised trial. J Bone Joint Surg Br. 1993 Sep;75(5):825-9.

26. Kinnard P, Gordon D. A Comparison between Chevron and Mitchell Osteotomies for Hallux Valgus. Foot Ankle. 1984 MarApr;4(5):241-3

27. Meier PJ, Kenzora JE. The risks and benefits of distal first metatarsal osteotomies. Foot Ankle. 1985 Aug;6(1):7-17. 